\title{
Preventing aspiration pneumonia in older people: do we have the 'know-how'?
}

\author{
James KH Luk *, Daniel KY Chan
}

\section{A B S T R A C T}

Aspiration pneumonia is common in older people. To reduce the risk of aspiration pneumonia, maintenance of good oral hygiene is important and medications affecting salivary flow or causing sedation are best avoided, if possible. The use of $\mathrm{H}_{2}$ blockers and proton-pump inhibitors should be minimised. Different compensatory and facilitation techniques can be applied during oral feeding. Hand feeding should be tried before consideration of tube feeding. The use of tube feeding is the last resort and is mainly for improving nutrition and hydration. Prevention of aspiration pneumonia and increasing survival rates should not be the rationales for tube feeding. Feeding via both gastrostomy and nasogastric tube has similar risks for aspiration pneumonia, and continuous pump feeding is not better than intermittent feeding. Jejunal feeding

This article was published on 4 Jul 2014 at www.hkmj.org. might decrease the chance of aspiration pneumonia in selected high-risk patients. If older patients are on angiotensin-converting enzyme inhibitors without intolerable cough, continuing the drug may be beneficial. Folate deficiency, if present, needs to be promptly corrected. Further better-designed studies are warranted to find the best ways for prevention of aspiration pneumonia.

\begin{tabular}{l} 
Hong Kong Med J 2014;20:421-7 \\
\hline DOI: 10.12809/hkmj144251 \\
1 JKH Luk *, FHKCP, FHKAM (Medicine) \\
2,3 DKY Chan, MD, FACP \\
${ }^{1}$ The University of Hong Kong; Department of Medicine and Geriatrics, \\
Fung Yiu King Hospital, 9 Sandy Bay Road, Pokfulam, Hong Kong \\
${ }^{2}$ Faculty of Medicine, University of New South Wales, High Street, \\
Kensington NSW 2052, Australia \\
${ }^{3}$ Aged Care and Rehabilitation, Bankstown-Lidcombe Hospital, Eldridge \\
Road, Bankstown NSW 2200, Australia \\
* Corresponding author: lukkh@ha.org.hk
\end{tabular}

\section{Introduction}

In Hong Kong, as in many other countries, there has been an increasing trend of older patients, especially from residential care homes for the elderly (RCHE), getting admitted to medical wards due to pneumonia. Pneumonia is the second commonest cause of death in Hong Kong. ${ }^{1}$ An overseas study revealed that a significant proportion of pneumonia in $\mathrm{RCHE}$ is related to aspiration pneumonia (AP). ${ }^{2}$ In the US, annual hospitalisation due to AP in the older population nearly doubled from 1991 to $1998 .^{3}$ The true incidence of AP is hard to ascertain because the criteria for diagnosis are not standardised. Often, an aspiration event is not witnessed; rather, it is suspected from a history of difficulty in swallowing.

\section{Pathophysiology of aspiration}

Aspiration is defined as inhalation of oropharyngeal or gastric contents into the pulmonary tree. Depending on the composition of the aspirates, three complications have been described. ${ }^{4}$ Chemical pneumonitis is the first complication and is the result of aspiration of acidic gastric contents. The severity depends on the $\mathrm{pH}$ value and quantity of aspirate. A $\mathrm{pH}$ of $<2.5$ and gastric volume of $>0.3 \mathrm{~L}$ per $\mathrm{kg}$ of body weight are needed to develop chemical pneumonitis. ${ }^{5}$ In addition to acid, stomach may have other particulate contents and aspiration of these contents may also lead to lung damage. There are two phases of lung changes after acid aspiration. In the first phase, there is direct toxic damage to the respiratory epithelium resulting in interstitial pulmonary oedema with ventilation/perfusion mismatch. ${ }^{4}$ The second phase occurs 2 to 3 hours later, and is characterised by inflammatory response with production of cytokines, neutrophil infiltration, and macrophage activation. ${ }^{6}$ Oxygen-free radicals are generated which, in turn, lead to further lung damage.

Some patients may remain asymptomatic after acid aspiration. Others may develop dyspnoea, pleuritic chest pain, cough, fever, bronchospasm, bloody or frothy sputum, respiratory failure and/or acute respiratory distress syndrome. Management of uncomplicated cases is usually supportive with airway clearance, oxygen, and positive pressure ventilation. Antibiotics do not alter the clinical outcome unless bacterial infection occurs. ${ }^{7}$ Bronchodilators can be used to treat bronchospasm if present, but there is little role for corticosteroids. ${ }^{8}$ Not uncommonly, it may not be clear whether the patient has chemical pneumonitis or bacterial pneumonia. In these situations, it is prudent to start empirical broadspectrum antibiotics.

The second complication of aspiration is 


\section{預防老年人的吸入性肺炎：是否有竅門？ 陸嘉熙、陳錦賢}

吸入性肺炎是老年人一種常見的病。為減少吸入性肺炎的風險, 口腔 衛生很重要。可以的話, 最好避免處方會影響唾液流量或有鎮靜作用 的藥物, 亦應盡量減少施以 $\mathrm{H}_{2}$ 受體阻滯劑和質子泵抑製劑。給予老年 人餵食的時候可使用不同的補償和加強技巧的方法。在考慮使用餵食 管前應先嘗試人手給予老年人餵食。餵食管主要用於改善老年人的營 養和提供水分, 應視之為不得已的方法, 而預防吸入性肺炎和提高存 活率也不應該是使用餵食管的理由。通過胃和鼻胃管餵養的風險與吸 入性肺炎類似, 連續性經泵輸入並不會比間歇餵食好。對於一些高危 患者, 空腸營養可能會減少吸入性肺炎發生的機會。如果年齡較大的 患者正接受血管緊張素轉換酶抑製劑而沒有不可容忍的咳嗽, 繼續服 食此等藥物可能為病人帶來好處。如缺乏葉酸, 應及時補充。須進行 更多設計合適的研究來探討預防吸入性肺炎的最佳方法。
AP which is either secondary bacterial infection following chemical pneumonitis or primary bacterial aspiration due to inhalation of oropharyngeal secretions or gastric contents contaminated with bacteria. ${ }^{4}$ Acid-associated pneumonitis favours the secondary development of AP by superinfection with bacteria following destruction of the epithelium. Bacterial infection is more common in older patients because of their impaired immunity, poor oral hygiene, and bacterial colonisation in the stomach due to low-acidity environment, especially when they are on histamine $\mathrm{H}_{2}$-receptor blockers $\left(\mathrm{H}_{2}\right.$ blocker) or proton-pump inhibitors (PPI). ${ }^{9}$

The third complication of aspiration is particleassociated aspiration which is the inhalation of particulate matters of the gastric content resulting in acute obstruction of smaller and, possibly, larger airways. The patients will have sudden arterial hypoxaemia with development of lung atelectasis.

\section{Aspiration pneumonia}

The most common areas of the lung affected are the posterior segment of the upper lobe and superior segment of the lower lobe, if aspiration occurs in a supine position. The lower segments of the lower lobe are often involved if aspiration occurs in a sitting position. ${ }^{10}$ The patients may have an insidious course with increased respiratory rate, foulsmelling sputum, haemoptysis, and fever. ${ }^{7}$ There is usually leukocytosis and raised C-reactive protein, and complications like exudative pleural effusion, empyema, and lung abscesses can occur. However, atypical presentation of AP is also common. ${ }^{11}$ Older patients may have impaired $\mathrm{T}$ cell function and hence, they may be unable to mount a febrile response. The mucociliary clearance of older people is also impaired, resulting in diminished sputum production and cough. Therefore, they can present non-specifically with different geriatric syndromes such as falls, incontinence, delirium, and decreased mobility or activity of daily living.

\section{Risk factors for aspiration pneumonia}

\section{Oral hygiene and aspiration pneumonia}

Bad oral hygiene is one of the important risk factors for AP. ${ }^{7}$ Indeed, about half of healthy adults aspirate saliva during sleep. ${ }^{12}$ If the person has normal immunity, good cough reflex, normal respiratory ciliary movement and good oral hygiene, there are usually no harmful effects of aspirating saliva. Unfortunately, oral hygiene is the least-considered aspect in hospitalised and institutionalised patients. ${ }^{13}$ Reduction in saliva flow leads to an increased concentration of bacteria in the oral cavity. Medications such as diuretics, anticholinergics, anxiolytics, and antipsychotics reduce salivary flow. In a Japanese study ${ }^{14}$ involving 71 edentulous older people, direct relationship between the number of decayed teeth and AP was reported, and tongue coating was a risk indicator for AP. All these point to the fact that bacterial flora in the oral cavity are related to AP. The microflora of the oral cavity include Gram-positive, Gram-negative, and anaerobic organisms. Hence, broad-spectrum antibiotics with good aerobic and anaerobic coverage are usually needed for AP treatment.

\section{Dysphagia and gag reflex}

Some studies show an association between swallowing dysfunction and AP, while others show that dysphagia is not sufficient to cause AP unless other risk factors are present. ${ }^{15} \mathrm{~A}$ recent metaanalysis of four cohort studies concluded that dysphagia was a serious risk factor for AP in frail older people, particularly in those suffering from cerebrovascular disease. ${ }^{16}$ The most common cause for oropharyngeal dysphagia in older people is neurological diseases including stroke, advanced dementia, and Parkinson's disease. ${ }^{17}$ Different diseases have different dysphagia trajectories and prognosis. Dysphagia resulting from stroke is mostly temporary; however, it is progressive in older patients with advanced dementia or Parkinson's disease.

Some studies report that abnormal gag reflex and cough reflex are associated with aspiration. ${ }^{18}$ However, other studies fail to confirm this correlation..$^{19}$ Hence, abnormal gag reflex may not be a reliable predictor of AP risk. Similarly, a study involving 107 in-patients from a rehabilitation hospital showed that bedside evaluation for risk of aspiration tends to underestimate the risk of aspiration with positive and negative predictive values of 0.75 and 0.7 , respectively. ${ }^{20}$ 


\section{Medications and aspiration pneumonia}

Medications such as diuretics, anticholinergics, anxiolytics, antipsychotics, and levodopa reduce salivary flow and increase bacterial flora in the oral cavity. Some medications, such as antipsychotics and anxiolytics, lead to impaired swallowing function due to the effects on the central nervous system and can increase the risk of AP. ${ }^{21}$ Barium is considered to be inert but barium aspiration has been reported during barium swallowing studies with severe chemical pneumonitis and death. ${ }^{22} \mathrm{~A}$ low $\mathrm{pH}$ environment is needed to kill the organisms that colonise the gastro-intestinal tract. Histamine $\mathrm{H}_{2}$ blockers and PPI increase the $\mathrm{pH}$ of the stomach, favouring the growth of bacteria. Increased risk of pneumonia in acute hospital patients using $\mathrm{H}_{2}$ blockers and PPI has been reported in a metaanalysis of eight observational studies. ${ }^{23}$

\section{Tube feeding and aspiration pneumonia: the all-time controversy}

In Hong Kong, many older patients are put on tube feeding when they are dysphagic or feeding inadequately. Risk of AP and decreased survival are the most frequently cited reasons by health care teams for starting tube feeding in older patients. ${ }^{24}$ To date, evidence has clearly proven that tube feeding, be it nasogastric (NG) or via gastrostomy, does not prevent AP. On the contrary, it has been shown that the incidence or risk of AP may be increased by the use of tube feeding. ${ }^{25}$ Placement of NG tube weakens the ability of the lower oesophageal sphincter to prevent gastro-oesophageal reflux. ${ }^{26}$ The use of tube feeding also leads to neglect of the oral hygiene. Moreover, partial pulling of the NG tube by confused elderly whilst the feeding is running can cause the feed to drip into the trachea, leading to AP. To date, studies have failed to demonstrate the survival benefits of tube feeding in older people. One study with gastrostomy revealed that only $38 \%$ of nursing home patients were alive at 1 year after feeding tube placement. ${ }^{27}$ In a local study performed by our group involving $312 \mathrm{RCHE}$ residents with advanced dementia, 164 (53\%) were on enteral feeding. ${ }^{28}$ The 1 -year mortality rate was $38 \%$ and enteral feeding was one of the important risk factors for 2-year mortality. ${ }^{28}$

\section{Ethical issues of tube feeding in frail older patients}

One may ask why tube feeding remains prevalent in Hong Kong among older patients. There are complex factors in the 'conceptual framework' behind this decision-making. Firstly, there are the family factors. Family members may think that they cannot let the demented relative starve to death. They may be too optimistic concerning the clinical course of their demented relative, and often, they are informed by physicians that the tube can be removed if patients regain their ability to eat normally. ${ }^{29}$ However, the chance of weaning off tube feeding is actually lower than $20 \%$ among all indications for tube placement. ${ }^{30}$ Secondly, physician factors may come into play. It is shown that $80 \%$ of physicians believe that clinical outcomes are improved by tube feeding while $40 \%$ think that tube feeding should continue even if other life-sustaining measures such as mechanical ventilation are ceased. ${ }^{31}$ Many physicians are under high pressure from family members and RCHE staff when they discuss about tube feeding. Some physicians recommend gastrostomy feeding as they believe it to have a lower risk of AP versus NG tube feeding. In addition, they may be afraid of legal consequences if demented patients are not fed with a feeding tube. Thirdly, cultural taboo of palliation as an option and lack of the concept of advance care planning are also important factors. In Hong Kong, advance directive is not commonly practised and hence, very few people have laid down their options for tube feeding in an advance directive. ${ }^{32}$ Fourthly, in Hong Kong, there are practical issues if we do not use tube feeding in some patients. If older patients are feeding poorly, there are difficulties in discharging them from hospitals, especially if they are going to RCHE. Many RCHE in Hong Kong do not have enough manpower to hand-feed their residents. Often, the RCHE staff will send their older residents back to the hospitals if they are eating poorly, leading to a 'revolving door syndrome' with high readmission rates after discharge from hospitals. Alternative ways of hydration including hypodermoclysis (subcutaneous fluid infusion) are not practised in local RCHE. ${ }^{33}$ In dysphagic patients, it is also very difficult to give oral medications to patients without a NG or gastrostomy tube.

\section{Assessment for aspiration}

Since bedside clinical evaluation alone may underestimate the frequency of aspiration, two reliable tests have been used to assess the risk of AP. $^{34}$ Videofluoroscopic swallowing study (VFSS) is the most commonly used test for this purpose. ${ }^{35}$ In VFSS, a patient's response to aspiration, silent aspiration, and effectiveness of airway protection manoeuvres with various types of barium-coated food can be assessed. In addition, oesophageal phase of swallowing can be visualised. It is more sensitive than bedside testing and is the 'gold standard' of swallowing assessment. The other procedure is the fibreoptic endoscopic evaluation of swallowing (FEES) which involves passing an endoscope through the nose to the level of the soft palate to directly visualise the pharynx and larynx, and observe the pharyngeal phase of swallowing. ${ }^{36}$ When FEES includes sensory testing using air 
pulse to trigger a swallowing response, it is named fibreoptic endoscopic evaluation of swallowing with sensory testing (FEEST). Both VFSS and FEES/ FEEST are equally accurate in detecting dysphagia and they have their independent advantages-VFSS is more widely available, non-invasive, and shows all phases of swallowing; while FEES/FEEST does not involve exposure to radiation, can be performed more frequently, and allows examiners to view the swallowing process in real time. Hence, the choice between VFSS and FEES/FEEST depends on the availability of the investigation, patient condition, and the expertise of the centre.

\section{Measures to prevention of aspiration pneumonia}

\section{Oral hygiene}

Maintaining a good oral hygiene is one of the important measures to prevent AP. Older people tend to have more dental caries, as well as gingival and periodontal diseases. ${ }^{37}$ Oral care in both edentate and dentate patients is equally important. A recent systematic review ${ }^{38}$ showed that tooth brushing, cleaning dentures, and oral health care were the best interventions to reduce AP. However, older people, in general, do not like to receive dental care. ${ }^{39}$ In Hong Kong, few older patients, especially those living in $\mathrm{RCHE}$, receive regular dental assessment and management. The reasons behind this include cost, lack of awareness in the general population about the importance of oral hygiene, and nonavailability of dentists for older patients in RCHE.

\section{Adjustment of medications}

Reducing the total number of medications and avoiding drugs that are known to cause decreased salivary flow can reduce the risk of AP. ${ }^{7}$ If possible, sedating medications are best avoided. Moreover, withholding medications that can raise the gastric $\mathrm{pH}$ seems to be useful in preventing AP. A recent meta-analysis ${ }^{40}$ showed increased risk of pneumonia in patients receiving ranitidine compared with those receiving sucralfate. Since PPI also reduce acid secretion, we may need to consider stopping PPI as soon as these are not necessary.

\section{Hand feeding and eating environment}

Assisted hand feeding provides a viable alternative to tube feeding, especially among demented patients. Indeed, patients with dysphagia who are orally fed have fewer episodes of aspiration than those fed by gastrostomy. ${ }^{41}$ Older patients with dementia can still form a relationship with their carers and touching, kissing, hugging, and responding to non-verbal cues by carers can influence the food intake of older people. ${ }^{42}$ The environment can also affect feeding. ${ }^{43}$
In an environment highly distracted by television, loud noises or conversations, older people are less likely to complete their meal. In addition, older patients are prone to delirium in noisy environments and this may further impair feeding. Unfortunately, the medical wards in Hong Kong public hospitals are often crowded and noisy, and distraction is very common during feeding. In the local setting of $\mathrm{RCHE}$, manpower issues and crowded environment also affect feeding among the RCHE residents.

\section{Dietary modification}

Food thickening, pureeing, and blending are usually recommended for dysphagic patients to reduce their risk of AP. However, the effectiveness in preventing AP has not been proven clinically. Diet modification with thickeners is expensive, while pureeing and blending are labour-intensive. Thickening agents affect bioavailability of medications, reduce the flavour of food, increase oral processing time, and increase feelings of fullness resulting in poor appetite. ${ }^{44}$ The Chinese believe that to eat well is to have good fortune in life, and these alternative 'foods' reduce the joy of eating. The authors' personal experience is that many older Chinese patients dislike the texture of thickened fluid and purees. This may lead to poor feeding among the older patients resulting in unintended side-effects of malnutrition, dehydration, and sub-therapeutic medication levels. In addition, we may have a false sense of security after dietary modifications as dysphagic patients who are given a pureed diet may still aspirate.

\section{Compensatory techniques}

It is important for older patients to sit upright when eating. For those who cannot get out of bed, raising the head of the bed by at least 30 degrees is the usual recommended practice. ${ }^{45}$ The chin-down or chin-tuck manoeuvre is widely used in dysphagia treatment. ${ }^{46}$ Tilting the body to the non-paralysed side (side-lying) and turning the head towards the paralysed side makes it easier to bring a food bolus downward and pass through the non-paralysed side. Speech therapists often teach dysphagic patients to use double or multiple swallowing. Other techniques include hard swallow, supraglottic swallow, and Mendelsohn manoeuvre.

\section{Facilitation techniques, exercises, and neurostimulation}

Mechanical or thermal stimulation at the anterior oropharynx can lead to reflex swallowing action. ${ }^{47}$ Based on this theory, cold, tactile, and pressure stimulation are used to facilitate swallowing. Different exercises have been advocated to improve the range of movement and strength of jaw, tongue, lip, palate, and vocal cords. ${ }^{48}$ 
Recently, two new neurostimulation approaches are being developed to improve the swallowing function by stimulating cortical neuroplasticity. ${ }^{49}$ These include stimulation of the peripheral oropharyngeal sensory system by chemical, physical or electrical stimuli, and direct stimulation of the pharyngeal motor cortex using repetitive transcranial magnetic stimulation. ${ }^{50}$ At this moment, we are awaiting more studies evaluating these new treatments in dysphagic patients.

\section{Aspiration pneumonia when using tube feeding}

As mentioned previously, tube feeding does not prevent AP, instead, it serves as an alternative to deliver nutrition. Raising the head of the bed to 30 degrees during tube feeding is usually practised. Although not proven by clinical trials, it is desirable to start feeding at a slow rate and with small amounts in the initial phase. Most clinical studies cannot find any differences in AP between patients receiving continuous pump feeding and those receiving intermittent feeding. ${ }^{51}$ A local study in 178 infirmary patients showed no difference in either pneumonia or death rates between the modes of feeding. ${ }^{52}$ Continuous pump feeding has a higher operating cost than intermittent feeding. Although individual older patients may tolerate continuous pump feeding, based on the evidence so far, we cannot recommend the use of continuous pump feeding solely for the purpose of preventing AP.

Checking gastric residual volume (RV) every 4 hours, and maintaining a residual level of less than $100 \mathrm{~mL}$ are usually advocated during tube feeding. However, it has been shown that the frequencies of regurgitation and aspiration are similar over a wide range of RV from 0 to $400 \mathrm{~mL}$. Hence, RV is not a reliable marker of aspiration. ${ }^{53}$ On the other hand, large-bore NG tubes may increase the risk of aspiration of gastric contents by interfering with normal lower oesophageal sphincter. ${ }^{54}$

In contrast to western countries, gastrostomy is not commonly performed in Hong Kong for various reasons, including the need for a gastrointestinal specialist for the procedure, small risk of surgical complications, lack of knowledge about and confidence among RCHE staff in taking care of the tube, and cost in buying replacement tube if dislodged. In the author's personal experience, many local clinicians believe gastrostomy feeding to be better than NG tube feeding in preventing AP. However, the current evidence fails to suggest any advantage of the former in AP prevention. A review comparing NG tube feeding with gastrostomy feeding could not find any differences in mortality and pneumonia between the two groups. ${ }^{55}$ On the other hand, feeding via percutaneous endoscopic gastrostomy with jejunal extension (PEGJ) might decrease the chance of aspiration in the selected high-risk group such as those with severe gastroparesis. ${ }^{56}$ Nevertheless, the use of PEGJ feeding is associated with many problems such as dumping syndrome, dislodgement and movement of the tube up to stomach. These complications limit its use in older patients.

\section{Pharmacological prevention of aspiration pneumonia}

Impaired dopamine metabolism may affect swallowing reflexes. It follows that drugs like amantadine and levodopa may be useful to improve swallowing. Administration of levodopa to patients with stroke can improve the swallowing reflex, while amantadine seems to be able to reduce the risk of pneumonia by $20 \%$ in stroke patients. ${ }^{57,58}$ However, both amantadine and levodopa have their own side-effects and additional trials are warranted to confirm their role in AP prevention. Cilostazol is a phosphodiesterase inhibitor which inhibits platelet aggregation and is a direct arterial vasodilator used in peripheral vascular diseases. Cilostazol may increase dopamine and substance $\mathrm{P}$ concentrations in the brain, which are important for the swallowing reflex. Studies on cilostazol for pneumonia prevention were mainly conducted in Japanese stroke patients. ${ }^{59-61}$ Cilostazol has a grade $\mathrm{C} 1$ recommendation in the Japanese Guidelines for the Management of Stroke 2009. ${ }^{62}$ Since potential serious complications like bleeding can occur, it is not recommended in other parts of the world for AP prevention. Folate, which affects dopamine metabolism, may lead to an impaired swallowing reflex when it is deficient. A 2-year non-randomised trial ${ }^{63}$ showed that folic acid can improve the latency of the swallowing reflex. Since folic acid supplement has minimal side-effects, it should be given to older patients with folate deficiency. Angiotensin-converting enzyme inhibitor (ACEI) reduces the degradation of bradykinin and tachykinin, including substance P. Accumulation of substance $P$ has a sensitising effect on cough and swallowing reflex. ${ }^{64}$ This effect is particularly prominent in Asians. Previous studies, ${ }^{65,66}$ mainly in stroke patients, suggest that ACEIs could reduce the risk of pneumonia. However, we still do not know the optimum dose of ACEI for preventing AP and its long-term efficacy. Metoclopramide can delay the development of pneumonia but has no effect on the frequency of pneumonia and the overall mortality in tube-feeding patients. ${ }^{67}$ Other prokinetic agents, including cisapride and erythromycin, can increase gastric emptying. ${ }^{68}$ However, no reduction in pneumonia frequency has been reported and we cannot conclude whether these medications can help prevent AP.

\section{Conclusion}

We do not have the complete 'know-how' in 
preventing AP among older patients. Aspiration pneumonia continues to occur commonly in our older patients, implying that our AP prevention strategies are not entirely effective. At present, we should provide an individual care plan to each elderly patient, based on our current knowledge. It is important to maintain a satisfactory oral hygiene and withhold unnecessary medications which will affect the salivary flow and cause sedation. The use of $\mathrm{H}_{2}$ blockers and PPI has to be minimised, if possible. Dietary modifications and compensatory and facilitation techniques can be used during feeding. Instead of starting tube feeding immediately, careful hand feeding may be tried in a quiet environment. It is best to keep the use of tube feeding as the last resort, mainly for improving nutrition and hydration. Prevention of AP and improving the chances of survival are not the rationales for placing feeding tubes. If tube feeding is deemed necessary, the 'start-low-and-go-slow' principle may be used. Both gastrostomy and NG tube feeding have similar risk for AP, and continuous pump feeding is not better than intermittent feeding. Feeding via PEGJ might decrease the chance of aspiration in selected high-risk patients. If older patients are on ACEIs without intolerable cough, continuing the drug may be beneficial. Folate deficiency, if present, needs to be promptly corrected. The use of other medications to prevent AP remains controversial and is not routinely practised. Further large-scale international and local studies are warranted to find the best ways of AP prevention among the older patients.

\section{References}

1. Department of Health, Hong Kong. Public Health Information and Statistics of Hong Kong. Available from: http://www.healthyhk.gov.hk/phisweb/plain/en/healthy_ facts/disease_burden/major_causes_death/major_causes_ death. Accessed 1 Mar 2014.

2. Marrie TJ. Pneumonia in the long-term-care facility. Infect Control Hosp Epidemiol 2002;23:159-64.

3. Baine WB, Yu W, Summe JP. Epidemiologic trends in the hospitalization of elderly Medicare patients for pneumonia, 1991-1998. Am J Public Health 2001;91:1121-3.

4. Janda $M$, Scheeren TW, Nöldge-Schomburg GF. Management of pulmonary aspiration. Best Pract Res Clin Anaesthesiol 2006;20:409-27.

5. James CF, Modell JH, Gibbs CP, Kuck EJ, Ruiz BC. Pulmonary aspiration-effects of volume and $\mathrm{pH}$ in the rat. Anesth Analg 1984;63:665-8.

6. Beck-Schimmer B, Rosenberger DS, Neff SB, et al. Pulmonary aspiration: new therapeutic approaches in the experimental model. Anesthesiology 2005;103:556-66.

7. Marik PE. Aspiration pneumonitis and aspiration pneumonia. N Engl J Med 2001;344:665-71.

8. Gates S, Huang T, CheneyFW.Effects of methylprednisolone on resolution of acid-aspiration pneumonitis. Arch Surg 1983;118:1262-5

9. Oh E, Weintraub N, Dhanani S. Can we prevent aspiration pneumonia in the nursing home? J Am Med Dir Assoc 2005;6(3 Suppl):S76-80.
10. Finegold SM. Aspiration pneumonia. Rev Infect Dis 1991;13 Suppl 9:S737-42.

11. Fein AM. Pneumonia in the elderly. Special diagnostic and therapeutic considerations. Med Clin North Am 1994;78:1015-33.

12. Gleeson K, Eggli DF, Maxwell SL. Quantitative aspiration during sleep in normal subjects. Chest 1997;111:1266-72.

13. Yoneyama T, Yoshida M, Ohrui T, et al. Oral care reduces pneumonia in older patients in nursing homes. J Am Geriatr Soc 2002;50:430-3.

14. Abe S, Ishihara K, Adachi M, Okuda K. Tongue-coating as risk indicator for aspiration pneumonia in edentate elderly. Arch Gerontol Geriatr 2008;47:267-75.

15. Langmore SE, Terpenning MS, Schork A, et al. Predictors of aspiration pneumonia: how important is dysphagia? Dysphagia 1998;13:69-81.

16. van der Maarel-Wierink CD, Vanobbergen JN, Bronkhorst EM, Schols JM, de Baat C. Meta-analysis of dysphagia and aspiration pneumonia in frail elders. J Dent Res 2011;90:1398-404.

17. Ertekin C, Aydogdu I. Neurophysiology of swallowing. Clin Neurophysiol 2003;114:2226-44.

18. Horner J, Brazer SR, Massey EW. Aspiration in bilateral stroke patients: a validation study. Neurology 1993;43:4303.

19. Terré R, Mearin F. Oropharyngeal dysphagia after the acute phase of stroke: predictors of aspiration. Neurogastroenterol Motil 2006;18:200-5.

20. Splaingard ML, Hutchins B, Sulton LD, Chaudhuri G. Aspiration in rehabilitation patients: videofluoroscopy vs bedside clinical assessment. Arch Phys Med Rehabil 1988;69:637-40

21. Aparasu RR, Chatterjee S, Chen H. Risk of pneumonia in elderly nursing home residents using typical versus atypical antipsychotics. Ann Pharmacother 2013;47:464-74.

22. Kawsar HI, Shahnewaz J, Ricaurte B, Daw HA. Barium aspiration. BMJ Case Rep 2012;2012. pii: bcr0220125891.

23. Eom CS, Jeon CY, Lim JW, Cho EG, Park SM, Lee KS. Use of acid-suppressive drugs and risk of pneumonia: a systematic review and meta-analysis. CMAJ 2011;183:3109.

24. Li I. Feeding tubes in patients with severe dementia. Am Fam Physician 2002;65:1605-11.

25. Vergis EN, Brennen C, Wagener M, Muder RR. Pneumonia in long-term care: a prospective case-control study of risk factors and impact on survival. Arch Intern Med 2001;161:2378-81.

26. Gomes GF, Pisani JC, Macedo ED, Campos AC. The nasogastric feeding tube as a risk factor for aspiration and aspiration pneumonia. Curr Opin Clin Nutr Metab Care 2003;6:327-33.

27. Mitchell SL, Tetroe JM. Survival after percutaneous endoscopic gastrostomy placement in older persons. J Gerontol A Biol Sci Med Sci 2000;55:M735-9.

28. Luk JK, Chan WK, Ng WC, et al. Mortality and health services utilisation among older people with advanced cognitive impairment living in residential care homes. Hong Kong Med J 2013;19:518-24.

29. Carey TS, Hanson L, Garrett JM, et al. Expectations and outcomes of gastric feeding tubes. Am J Med 2006;119:527. e11-6.

30. Wolfsen HC, Kozarek RA, Ball TJ, Patterson DJ, Botoman VA, Ryan JA. Long-term survival in patients undergoing percutaneous endoscopic gastrostomy and jejunostomy. 
Am J Gastroenterol 1990;85:1120-2.

31. Solomon MZ, O’Donnell L, Jennings B, et al. Decisions near the end of life: professional views on life-sustaining treatments. Am J Public Health 1993;83:14-23.

32. Chu LW, Luk JK, Hui E, et al. Advance directive and endof-life care preferences among Chinese nursing home residents in Hong Kong. J Am Med Dir Assoc 2011;12:14352.

33. Luk JK, Chan FH, Chu LW. Is hypodermoclysis suitable for frail Chinese elderly? Asian J Gerontol Geriatr 2008;3:4950.

34. Teramoto S, Fukuchi Y. Detection of aspiration and swallowing disorder in older stroke patients: simple swallowing provocation test versus water swallowing test. Arch Phys Med Rehabil 2000;81:1517-9.

35. Kim SY, Kim TU, Hyun JK, Lee SJ. Differences in videofluoroscopic swallowing study (VFSS) findings according to the vascular territory involved in stroke. Dysphagia 2014 Mar 29. Epub ahead of print.

36. Leder SB. Serial fiberoptic endoscopic swallowing evaluations in the management of patients with dysphagia. Arch Phys Med Rehabil 1998;79:1264-9.

37. Palmer LB, Albulak K, Fields S, Filkin AM, Simon S, Smaldone GC. Oral clearance and pathogenic oropharyngeal colonization in the elderly. Am J Respir Crit Care Med 2001;164:464-8.

38. van der Maarel-Wierink CD, Vanobbergen JN, Bronkhorst EM, Schols JM, de Baat C. Oral health care and aspiration pneumonia in frail older people: a systematic literature review. Gerodontology 2013;30:3-9.

39. Kiyak HA, Reichmuth M. Barriers to and enablers of older adults' use of dental services. J Dent Educ 2005;69:975-86.

40. Huang J, Cao Y, Liao C, Wu L, Gao F. Effect of histamine2-receptor antagonists versus sucralfate on stress ulcer prophylaxis in mechanically ventilated patients: a metaanalysis of 10 randomized controlled trials. Crit Care 2010;14:R194.

41. DiBartolo MC. Careful hand feeding: a reasonable alternative to PEG tube placement in individuals with dementia. J Gerontol Nurs 2006;32:25-33; quiz 34-5.

42. Lange-Alberts ME, Shott S. Nutritional intake. Use of touch and verbal cuing. J Gerontol Nurs 1994;20:36-40.

43. Amella EJ. Factors influencing the proportion of food consumed by nursing home residents with dementia. J Am Geriatr Soc 1999;47:879-85.

44. Cichero JA. Thickening agents used for dysphagia management: effect on bioavailability of water, medication and feelings of satiety. Nutr J 2013;12:54.

45. Carnaby G, Hankey GJ, Pizzi J. Behavioural intervention for dysphagia in acute stroke: a randomised controlled trial. Lancet Neurol 2006;5:31-7.

46. Shanahan TK, Logemann JA, Rademaker AW, Pauloski BR, Kahrilas PJ. Chin-down posture effect on aspiration in dysphagic patients. Arch Phys Med Rehabil 1993;74:7369.

47. Teismann IK, Steinsträter $\mathrm{O}$, Warnecke $\mathrm{T}$, et al. Tactile thermal oral stimulation increases the cortical representation of swallowing. BMC Neurosci 2009;10:71.

48. Hägg M, Anniko M. Lip muscle training in stroke patients with dysphagia. Acta Otolaryngol 2008;128:1027-33.

49. Rofes L, Vilardell N, Clavé P. Post-stroke dysphagia: progress at last. Neurogastroenterol Motil 2013;25:278-82.

50. Rhee WI, Won SJ, Ko SB. Diagnosis with manometry and treatment with repetitive transcranial magnetic stimulation in dysphagia. Ann Rehabil Med 2013;37:90712.

51. MacLeod JB, Lefton J, Houghton D, et al. Prospective randomized control trial of intermittent versus continuous gastric feeds for critically ill trauma patients. J Trauma 2007;63:57-61.

52. Lee JS, Kwok T, Chui PY, et al. Can continuous pump feeding reduce the incidence of pneumonia in nasogastric tube-fed patients? A randomized controlled trial. Clin Nutr 2010;29:453-8.

53. McClave SA, Lukan JK, Stefater JA, et al. Poor validity of residual volumes as a marker for risk of aspiration in critically ill patients. Crit Care Med 2005;33:324-30

54. Ibáñez J, Peñafiel A, Marsé P, Jordá R, Raurich JM, Mata F. Incidence of gastroesophageal reflux and aspiration in mechanically ventilated patients using smallbore nasogastric tubes. JPEN J Parenter Enteral Nutr 2000;24:103-6.

55. Gomes CA Jr, Lustosa SA, Matos D, et al. Percutaneous endoscopic gastrostomy versus nasogastric tube feeding for adults with swallowing disturbances. Cochrane Database Syst Rev 2010;(11):CD008096.

56. Lin F, Luk JK, Ng MM, Chan FH. Jejunal feeding for an elderly man with advanced Parkinson's disease. Asian J Gerontol Geriatr 2013;8:50-3.

57. Kobayashi H, Nakagawa T, Sekizawa K, Arai H, Sasaki H. Levodopa and swallowing reflex. Lancet 1996;348:1320-1.

58. Nakagawa T, Wada H, Sekizawa K, Arai H, Sasaki H. Amantadine and pneumonia. Lancet 1999;353:1157.

59. Teramoto S, Yamamoto H, Yamaguchi Y, et al. Antiplatelet cilostazol, an inhibitor of type III phosphodiesterase, improves swallowing function in patients with a history of stroke. J Am Geriatr Soc 2008;56:1153-4.

60. Shinohara Y. Antiplatelet cilostazol is effective in the prevention of pneumonia in ischemic stroke patients in the chronic stage. Cerebrovasc Dis 2006;22:57-60.

61. Yamaya M, Yanai M, Ohrui T, Arai H, Sekizawa K, Sasaki $\mathrm{H}$. Antithrombotic therapy for prevention of pneumonia. J Am Geriatr Soc 2001;49:687-8.

62. Uchiyama S. Japanese Guidelines for the Management of Stroke 2009 [in Japanese]. Nihon Ronen Igakkai Zasshi 2011;48:633-6.

63. Sato E, Ohrui T, Matsui T, Arai H, Sasaki H. Folate deficiency and risk of pneumonia in older people. J Am Geriatr Soc 2001;49:1739-40.

64. Tomaki $M$, Ichinose $M$, Miura $M$, et al. Angiotensin converting enzyme (ACE) inhibitor-induced cough and substance P. Thorax 1996;51:199-201.

65. Harada J, Sekizawa K. Angiotensin-converting enzyme inhibitors and pneumonia in elderly patients with intracerebral hemorrhage. J Am Geriatr Soc 2006;54:175-6.

66. Caldeira D, Alarcão J, Vaz-Carneiro A, Costa J. Risk of pneumonia associated with use of angiotensin converting enzyme inhibitors and angiotensin receptor blockers: systematic review and meta-analysis. BMJ 2012;345:e4260.

67. Yavagal DR, Karnad DR, Oak JL. Metoclopramide for preventing pneumonia in critically ill patients receiving enteral tube feeding: a randomized controlled trial. Crit Care Med 2000;28:1408-11.

68. MacLaren R, Kuhl DA, Gervasio JM, et al. Sequential single doses of cisapride, erythromycin, and metoclopramide in critically ill patients intolerant to enteral nutrition: a randomized, placebo-controlled, crossover study. Crit Care Med 2000;28:438-44. 